\title{
Emergy analysis of a silvo-pastoral system, a case study in southern Portugal
}

Ana Margarida P. Fonseca, Carlos A. F. Marques, Teresa Pinto-Correia, Daniel E. Campbell

Abstract: The Mediterranean silvo-pastoral system known as Montado, in Portugal, is a complex land use system composed of an open tree stratum in various densities and an herbaceous layer, used for livestock grazing. Livestock also profit from the acorns, and the grazing contributes to avoid shrub encroachment. In the last 20 years, subsidies from the European Union have greatly promoted cattle rearing in this system and the introduction of heavy breeds, at the expense of sheep, goats or the native cattle breeds. The balance of the traditional system is thus threatened, and a precise assessment of the balance between the different components of the system, therefore is highly needed. The goal of this study was to gain a better understanding of a Montado farm system with cattle rearing as the major economic activity by applying the emergy evaluation method to calculate indices of yield, investment, environmental loading and sustainability. By integrating different ecosystem components, the emergy evaluation method allows a comprehensive evaluation of this complex and multifunctional system at the scale of an individual farm. This method provides a set of indices that can help us understand the system and design management strategies that maximize emergy flow in the farm. In this paper, we apply the emergy evaluation method to a Montado farm with cattle rearing, as a way to gain a better understanding of this system at the farm scale. The value for the transformity of veal

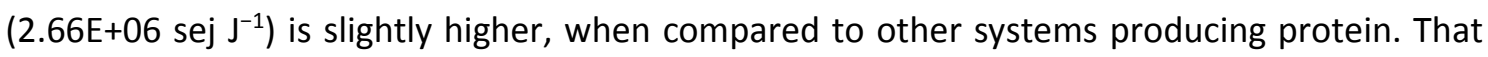
means that the investment of nature and man in this product was higher and it requires a premium price on the market. The renewability for Holm Oaks Farm (49\%), lower than for other similar systems, supports the assumption that this is a farm in which, comparing with others, the number of purchased inputs in relation to renewable inputs provided by nature, is higher. The Emergy Investment Ratio is 0.91 for cattle rearing compared to a value of 0.49 for cork and 0.43 for firewood harvesting, making it clear that cattle rearing is a more labor demanding activity comparing with extractive activities as cork and firewood harvesting.

Keywords; Montado- Emergy- Cattle rearing -Multifunctionality- Intensification

\section{doi: $10.1007 / \mathrm{s} 10457-015-9888-5$}

Citação: Fonseca A.M., Marques C., Pinto-Correia T. and Campbell D., 2015. Emergy analysis of a silvo-pastoral system, a case study in southern Portugal. Agroforestry Systems. DOI:10.1007/s10457-015-9888-5 